\title{
Front Matter: Volume 10966
}

, "Front Matter: Volume 10966," Proc. SPIE 10966, Electroactive Polymer Actuators and Devices (EAPAD) XXI, 1096601 (27 June 2019); doi: 10.1117/12.2524992

Event: SPIE Smart Structures + Nondestructive Evaluation, 2019, Denver, Colorado, United States 


\title{
PROCEEDINGS OF SPIE
}

\section{Electroactive Polymer Actuators and Devices (EAPAD) XXI}

\author{
Yoseph Bar-Cohen \\ lain A. Anderson \\ Nancy L. Johnson \\ Editors
}

\section{4-7 March 2019 \\ Denver, Colorado, United States}

Sponsored by

SPIE

Cosponsored by

OZ Optics, Ltd. (United States)

Polytec, Inc. (United States)

Cooperating Organizations

Jet Propulsion Laboratory (United States)

Colorado Photonics Industry Association (United States)

Published by

SPIE 
The papers in this volume were part of the technical conference cited on the cover and title page. Papers were selected and subject to review by the editors and conference program committee. Some conference presentations may not be available for publication. Additional papers and presentation recordings may be available online in the SPIE Digital Library at SPIEDigitalLibrary.org.

The papers reflect the work and thoughts of the authors and are published herein as submitted. The publisher is not responsible for the validity of the information or for any outcomes resulting from reliance thereon.

Please use the following format to cite material from these proceedings:

Author(s), "Title of Paper," in Electroactive Polymer Actuators and Devices (EAPAD) XXI, edited by Yoseph Bar-Cohen, lain A. Anderson, Nancy L. Johnson, Proceedings of SPIE Vol. 10966 (SPIE, Bellingham, WA, 2019) Seven-digit Article CID Number.

ISSN: 0277-786X

ISSN: 1996-756X (electronic)

ISBN: 9781510625877

ISBN: 9781510625884 (electronic)

Published by

SPIE

P.O. Box 10, Bellingham, Washington 98227-0010 USA

Telephone +1 3606763290 (Pacific Time) · Fax +1 3606471445

SPIE.org

Copyright @ 2019, Society of Photo-Optical Instrumentation Engineers.

Copying of material in this book for internal or personal use, or for the internal or personal use of specific clients, beyond the fair use provisions granted by the U.S. Copyright Law is authorized by SPIE subject to payment of copying fees. The Transactional Reporting Service base fee for this volume is $\$ 18.00$ per article (or portion thereof), which should be paid directly to the Copyright Clearance Center (CCC), 222 Rosewood Drive, Danvers, MA 01923. Payment may also be made electronically through CCC Online at copyright.com. Other copying for republication, resale, advertising or promotion, or any form of systematic or multiple reproduction of any material in this book is prohibited except with permission in writing from the publisher. The CCC fee code is 0277 $786 \mathrm{X} / 19 / \$ 18.00$.

Printed in the United States of America by Curran Associates, Inc., under license from SPIE.

Publication of record for individual papers is online in the SPIE Digital Library.

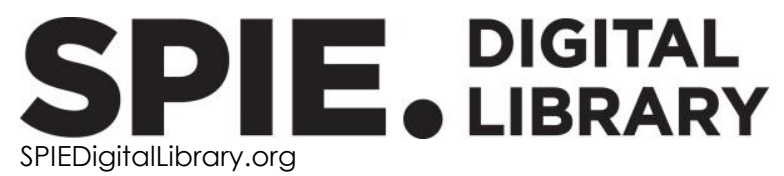

Paper Numbering: Proceedings of SPIE follow an e-First publication model. A unique citation identifier (CID) number is assigned to each article at the time of publication. Utilization of CIDs allows articles to be fully citable as soon as they are published online, and connects the same identifier to all online and print versions of the publication. SPIE uses a seven-digit CID article numbering system structured as follows:

- The first five digits correspond to the SPIE volume number.

- The last two digits indicate publication order within the volume using a Base 36 numbering system employing both numerals and letters. These two-number sets start with $00,01,02,03,04$, 05, 06, 07, 08, 09, OA, OB ... 0Z, followed by 10-1Z, 20-2Z, etc. The CID Number appears on each page of the manuscript. 


\title{
Contents
}

\author{
vii Authors \\ ix Conference Committee \\ xiii Introduction \\ xvii Appendix: The 2017 EAP-in-Action Program
}

KEYNOTE SESSION: EAP AS EMERGING ACTUATORS

1096603 Inflatable technology: using flexible materials to make large structures (Keynote Paper) [10966-2]

EAP MATERIALS AND DEVICES FABRICATION METHODS (E.G., 3D PRINTING): PROGRESS AND CHALLENGES

1096607 Investigation of stencil/ screen printing of silver (Ag) electrodes for ionic polymer metal composites (IPMCs) [10966-6]

1096608 Optimization and characterization of inkjet-printed ferroelectric capacitor for human body detection [10966-7]

\section{DESIGN METHODS OF PRODUCING EAP MECHANISMS}

10966 OM Design of reliable silicone elastomers for dielectric elastomers and stretchable electronics (Invited Paper) [10966-9]

10966 ON A novel design concept to boost the force output of dielectric elastomer membrane actuators [10966-10]

10966 OP Contactless coupling of dielectric elastomer membranes with magnetic repulsion [10966-96]

TWISTED AND COILED POLYMER ACTUATORS

10966 OR Investigation of manufacturing parameters for copper-wound super-coiled polymer actuators [10966-13] 
10966 OS A modular twisted and coiled polymer actuator unit for robotic tentacles [10966-14]

10966 OU Experimental investigation of temperature-dependent hysteresis of fishing-line artificial muscle (twisted and coiled polymer fiber) actuator [10966-16]

\section{MODELING}

10966 OV Numerical studies on origami dielectric elastomer actuator using Kresling pattern [10966-17]

10966 OW Finite element simulation of plane strain dielectric elastomer membranes actuated by discretized electrodes [10966-18]

10966 OX Effects of variation of permittivity and the actuating voltage on the dynamic response of dielectric elastomer actuator [10966-19]

10966 OY Continuum electro-mechanical damage modelling for dielectric elastomer [10966-20]

1096602 A dynamic model of helical dielectric elastomer actuator [10966-21]

$1096610 \quad$ Electromechanical hysteresis model and identification for soft dielectric elastomer actuator [10966-22]

\section{TESTING AND CHARACTERIZATION OF EAP MATERIALS}

1096614 Taming the viscoelastic creep of dielectric elastomer actuators [10966-25]

1096616 Fatigue life performances of silicone elastomer membranes for dielectric elastomer transducers: preliminary results [10966-27]

1096617 Characterization of dielectric elastomer actuators made of slide ring materials [10966-28]

MANUFACTURING, MECHANICAL PROPERTIES, AND PERFORMANCE OF EAP MATERIALS

1096619 Mechanical properties of slide-ring materials for dielectric elastomer actuators [10966-30]

10966 1A Measurement of strain distribution of dielectric elastomer actuator with plural pairs of electrodes via the image correlation method [10966-31]

IONIC EAP MATERIALS INCLUDING IPMC

10966 1C Modelling and control of self-sensing ionic electroactive polymer actuator [10966-33]

iv 
10966 1E Ionic buoyancy engines: finite element modeling and experimental validation [10966-35]

$109661 \mathrm{H} \quad$ Finite difference method and finite element method for modeling IPMC sensor voltage [10966-38]

\section{APPLICATION OF EAP TO ROBOTICS}

$109661 \mathrm{~K} \quad$ Searching for clues about Maxwell stress in the back-relaxation of ionic polymer-metal composites [10966-89]

\section{APPLICATIONS OF EAP I}

1096610 Experimental determination of material parameters for an enhanced modeling of polyelectrolyte gels [10966-81]

10966 IP Monolithic and active soft structures capable of self-actuation and self-adhesion [10966-45]

$109661 Q \quad$ Soft gripper actuated by electro-hydraulic force [10966-46]

10966 is Design of a dielectric elastomer actuator driven pneumatic pump [10966-48]

\section{WEARABLE AND TACTILE APPLICATIONS}

10966 IT Necessary dielectric elastomer parameters for wearable tremor suppression [10966-49]

10966 IV Low-cost and scalable fabrication of wearable soft sensor for neck mobility measurement [10966-51]

10966 IW Large-area, flexible, integrable and transparent DEAs for haptics [10966-52]

\section{APPLICATIONS OF EAP II}

10966 IY Dynamically reconfigurable DEAs incorporating shape memory polymer fibers [10966-54]

$109661 \mathrm{Z}$ High-voltage photonic switching of dielectric elastomers with amorphous silicon thin-films [10966-55]

\section{EAP ACTUATORS}

1096622 Simulation-driven design to reduce pull-in voltage of donut HASEL actuators [10966-58] 
APPLICATIONS OF EAP III

1096625 Silicone elastomer map: design the ideal elastomer [10966-61]

1096626 Synthetic Muscle Electroactive Polymer (EAP) based actuation and pressure sensing for prosthetic and robotic gripper applications [10966-62]

$1096629 \quad$ Bioinspired bistable soft actuators [10966-95]

\section{EAP SENSORS AND ACTUATORS}

10966 2D Electrostatic actuator for tactile display based on hydraulically coupled dielectric fluids and soft structures [10966-68]

\section{APPLICATIONS OF EAP IV}

$1096621 \quad$ Design, fabrication, and customized driving of dielectric loudspeaker arrays [10966-73]

\section{POSTER SESSION}

1096625 Drop-on-demand lift-off patterning of compliant electrodes [10966-84]

$109662 \mathrm{~T} \quad$ Abatement of high-voltage leakage current in electrostrictive fluorinated polymers through electro-annealing [10966-85]

$109662 \mathrm{U} \quad$ Live-mirror shape correction technology operated through modified electroactive polymer actuators [10966-87]

10966 2V Plane-strain deformations of ionic polymer-metal composites [10966-88]

$109662 X \quad$ Force optimization and numerical validation of helical dielectric elastomer actuator [10966-92] 


\section{Authors}

Numbers in the index correspond to the last two digits of the seven-digit citation identifier (CID) article numbering system used in Proceedings of SPIE. The first five digits reflect the volume number. Base 36 numbering is employed for the last two digits and indicates the order of articles within the volume. Numbers start with 00, 01, 02, 03, 04, 05, 06, 07, 08, 09, 0A, OB...0Z, followed by 10-1Z, 20-2Z, etc.

Aabloo, Alvo, 1C

Abu Shammeh, Rami A., $1 \mathrm{~V}$

Acome, Eric, 22

Agostini, Lorenzo, OY, 16

Akl, James, 1E

Akle, Barbar, $1 \mathrm{E}$

Aksoy, Bekir, $1 Y$

Alladkani, Fadi, $1 \mathrm{E}$

Al-Nasri, lyad, $1 \mathrm{~V}$

Anderson, lain A., 14, 2S

Ankit, Ankit, IW

Arango, Y., 08

Asaka, Kinji, OU, $1 \mathrm{H}$

Audigier, D., $2 \mathrm{U}$

Augoulas, Evangelos I., 07

Baba, Kazumasa, 17

Berselli, Giovanni, 16

Boldini, Alain, 1K, 2V

Bowers, Matthew, 26

Cao, Chongjing, OP

Capsal, Jean-Fabien, 08, 2T, 2 U

Carpenter, Ryan, 26

Cha, Youngsu, 1K, 1Q

Chan, Jun YU, IW

Chen, Xiaoyu, OX

Chen, Yi, 16

Conn, Andrew T., OP, $1 \mathrm{Z}$

Cottinet, Pierre-Jean, 2T, 2U

d'Almeida, Jesse, 26

de Lange, Rick C., 07

Dirè, Sandra, 2D

Divo, Eduardo, OV, $\mathrm{OZ}$

Drakunov, Sergey, $0 Z$

El Atrache, Abdullah, $0 Z$

Endl, Christian, 2l

Erfkamp, Jan, 10

Fambri, Luca, 2D

Fontana, Marco, OY, 16, 2D

Fritsch, Lionel, 08

Gandhi, Umesh, 22

Gao, Xing, OP

Ghosh, T. K., 29

Gillespie, C., $1 Z$

Guenther, Margarita, 10

Guo, J., IP

Hau, S., ON, is

Hayashi, T., IA

Homburg, Erik F.G.A., 07

Inove, Katsunari, 19
Irisawa, Toshihira, oU

Ishida, Makoto, 19

Ito, Kohzo, 19

Jayatissa, Sahan, 25

Johanson, Urmas, $1 \mathrm{C}$

Kauffman, Jeffrey L., $1 T$

Kelley, Christopher R., $1 T$

Keplinger, Christoph, 22

Kim, Daewon, 0V, 0Z, 2X

Klug, Florian, 21

Kondo, Kota, $1 \mathrm{H}$

Krisnadi, Febby, $1 \mathrm{~W}$

Kuhn, J. R., 2U

Ladegaard Skov, Anne, 0M, 25

Lau, Henry Y. K., OX

Le, Minh-Quyen, 2T, $2 \mathrm{U}$

Li, Fucai, 10

Li, Hongguang, 10

Li, Zezhou, OX

Linnebach, P., ON, 15

Litteken, Douglas A., 03

Liv, C., 19

Loew, Philipp, OW

Mark, Patrick S., 26

Marrani, Alessio, 2T

Martin, Darold, 26

Martinez, Ricardo, oV

Martino, Greig, 26

Marzo, A., $1 \mathrm{Z}$

Mascaro, Stephen A., OR

Masuya, Ken, oU

Mathews, Nripan, $1 \mathrm{~W}$

Matsuno, Koya, 17

Mau, Beatrice, 10

Mayumi, K., 19

Mazurek, Piotr, OM, 25

Meng, Lili, 10

Meniglio, Devid, 2D

Moretti, Giacomo, 16, 2D

Moretto, G., $2 U$

Moy, Leon, 26

Nakai, Takanori, 19

Nakamura, T., $1 \mathrm{~A}$

Nguyen, Linh Lan, $1 \mathrm{~W}$

Nodarse, Robert, 26

Oiwa, Chihaya, ou

Okui, M., 1 A

Padgett, Matthew E., OR

Panwar, Shardul, 22 
Park, JangHo, OV

Park, Tongil, $1 Q$

Pedroli, Francesco, 2T

Petit, L., $2 \mathrm{U}$

Pickery-Jordan, Jared, $2 S$

Porfiri, Maurizio, 1K, 2V

Poulin, Alexandre, 14

Price, Aaron D., 1V

Prillaman, Daniel L., 26

Punning, Andres, $1 \mathrm{C}$

Rasmussen, Lenore, 26

Rizzello, Gianluca, 0N, OW, OY, is

Rodriguez, Simone, 26

Rosen, Maxwell, $1 \mathrm{~K}$

Rosset, Samuel, 14, 25

Rossiter, J., 1P, $1 \mathrm{Z}$

Rowe, Michael, 22

Saadaoui, Mohamed, 08

Sanseau, Olivier, 2T

Scarpa, F., 1 Z

Scheiber, Cole, 26

Schlaak, Helmut F., 21

Seelecke, Stefan, ON, OW, OY, is

S., Sunjai Nakshatharan, $1 \mathrm{C}$

Shao, H., 29

Shea, Herbert, 14, $1 Y$

Shintake, Jun, 17

Shioya, Masatoshi, OU

Sideris, Eva A., 07

Sikulskyi, Stanislav, OV, 2X

Simone, Filomena, OW

Sîrbu, Ion-Dan, 2D

Smith, Damaris, 26

Solano-Arana, Susana, 21

Tahara, Kenji, OU

Takagi, Kentaro, $\mathrm{OU}, 1 \mathrm{H}$

Takeuchi, Hiromitsu, 17, 19

Tanizaki, Hoshito, OU

Thetpraphi, K., $2 \mathrm{U}$

Trejos, Ana-Luisa, IV

Urayama, Kenji, 19

Vaicekauskaite, Justina, 25

van Maris, Marc P.F.H.L, 07

Vertechy, Rocco, OY, 16, 2D

Vudayagiri, Sindhu, OM, 25

Wallmersperger, Thomas, 10

Walton, David, IV

Wang, Xuemin, OS

Wei, S., 29

Wu, Lianjun, OS

Xiang, C., 1P

Yokoyama, Hideaki, 19

Yonehara, Y., $1 \mathrm{~A}$

Zhu, Zicai, $1 \mathrm{H}$ 


\title{
Conference Committee
}

\author{
Symposium Chairs
}

Tribikram Kundu, The University of Arizona (United States)

Gregory W. Reich, Air Force Research Laboratory (United States)

Symposium Co-chairs

Zoubeida Ounaies, The Pennsylvania State University (United States) Hoon Sohn, KAIST (Korea, Republic of)

Conference Program Committee

Barbar J. Akle, Lebanese American University (Lebanon)

Kinji Asaka, National Institute of Advanced Industrial Science and Technology (Japan)

Pavol Baver, Technische Universiteit Delft (Netherlands)

Siegfried G. Bauer, Johannes Kepler Universität Linz (Austria)

Ray H. Baughman, The University of Texas at Dallas (United States)

Václav Bouda, Czech Technical University in Prague (Czech Republic)

Federico Carpi, Università degli Studi di Firenze (Italy)

Suresh Chandra, Institute of Technology, Banaras Hindu University (India)

Hyouk Ryeol Choi, Sungkyunkwan University (Korea, Republic of)

Gal deBotton, Ben-Gurion University of the Negev (Israel)

Toribio Fernández Otero, Universidad Politécnica de Cartagena (Spain)

Yahya A. Ismail, A'Shargiyah University (Oman)

Edwin W. H. Jager, Linköpings universitet (Sweden)

Giedrius Janusas, Kaunas University of Technology (Lithuania)

Kwang Jin Kim, University of Nevada, Las Vegas (United States)

Gabor M. Kovacs, EMPA (Switzerland)

Maarja Kruusmaa, University of Tartu (Estonia)

Jinsong Leng, Harbin Institute of Technology (China)

John D. W. Madden, The University of British Columbia (Canada)

Qibing Pei, University of California, Los Angeles (United States)

Thelge Chaminda Peiris, MAS Innovation Ltd. (Sri Lanka)

Valentin Radu, Omicron Plus S.R.L. (Romania)

Mehdi Razzaghi-Kashani, Tarbiat Modares University

(Iran, Islamic Republic of)

Jonathan M. Rossiter, University of Bristol (United Kingdom)

Anuvat Sirivat, Chulalongkorn University (Thailand) 
Anne Ladegaard Skov, Danmarks Tekniske Universitet (Denmark)

Geoffrey M. Spinks, University of Wollongong (Australia)

Ji Su, NASA Langley Research Center (United States)

Minoru Taya, University of Washington (United States)

I-Hsiang Tseng, Feng Chia University (Taiwan)

Rocco Vertechy, Università degli Studi di Bologna (Italy)

Frédéric Vidal, Université de Cergy-Pontoise (France)

Thomas Wallmersperger, Technische Universität Dresden (Germany)

Qiming M. Zhang, The Pennsylvania State University (United States)

Jian Zhu, National University of Singapore (Singapore)

Pawel Zylka, Wroclaw University of Technology (Poland)

\section{Session Chairs}

1 Keynote Session: EAP as Emerging Actuators

Yoseph Bar-Cohen, Jet Propulsion Laboratory (United States)

Iain A. Anderson, The University of Auckland (New Zealand)

2 EAP Materials and Devices Fabrication Methods (e.g., 3D Printing):

Progress and Challenges

Geoffrey M. Spinks, University of Wollongong (Australia)

Ray H. Baughman, The University of Texas at Dallas (United States)

3 Design Methods of Producing EAP Mechanisms

Gursel Alici, University of Wollongong (Australia)

Douglas A. Litteken, NASA Johnson Space Center (United States)

4 Twisted and Coiled Polymer Actuators

Helmut F. Schlaak, Technische Universität Darmstadt (Germany)

Nancy L. Johnson, General Motors Company (United States)

$5 \quad$ Modeling

Anne Ladegaard Skov, Technical University of Denmark (Denmark)

Herbert R. Shea, Ecole Polytechnique Fédérale de Lausanne

(Switzerland)

6 Testing and Characterization of EAP Materials

Piotr Mazurek, Danmarks Tekniske Universitet (Denmark)

Iain A. Anderson, The University of Auckland (New Zealand)

7 Manufacturing, Mechanical Properties, and Performance of EAP Materials

Yanju Liu, Harbin Institute of Technology (China)

Katherine E. Wilson, The University of Auckland (New Zealand) 
8 Ionic EAP Materials Including IPMC

Taeseon Hwang, University of Nevada, Las Vegas (United States)

Lenore Rasmussen, Ras Labs., LLC (United States)

9A Application of EAP to Robotics

Samuel Rosset, The University of Auckland (New Zealand)

Vishnu Baba Sundaresan, The Ohio State University (United States)

9B Applications of EAP I

Adrian Koh, National University of Singapore (Singapore)

Jang Ho Park, Embry-Riddle Aeronautical University (United States)

10A Wearable and Tactile Applications

John D. W. Madden, The University of British Columbia (Canada)

Claire Jean-Mistral, Institut National des Sciences Appliquées de Lyon (France)

10B Applications of EAP II

Christoph Keplinger, University of Colorado Boulder (United States)

Holger Böse, Fraunhofer-Institut für Silicatforschung ISC (Germany)

11 A EAP Actuators

Seyed Mirvakili, Massachusetts Institute of Technology (United States)

Ji Su, NASA Langley Research Center (United States)

11 B Applications of EAP III

E.-F. Markus Henke, The University of Auckland (Germany)

Seyed Mirvakili, Massachusetts Institute of Technology (United States)

12A EAP Sensors and Actuators

Edwin W. H. Jager, Linköpings universitet (Sweden)

Zihang Peng, University of California, Los Angeles (United States)

12B Applications of EAP IV

Rocco Vertechy, Università degli Studi di Bologna (Italy)

Edwin W. H. Jager, Linköpings universitet (Sweden) 
Proc. of SPIE Vol. 10966 1096601-12 Downloaded From: https://www.spiedigitallibrary.org/conference-proceedings-of-spie on 26 Apr 2023
Terms of Use: https://www.spiedigitallibrary.org/terms-of-use 


\section{Introduction}

The SPIE's Electroactive Polymers Actuators and Devices (EAPAD) Conference continues to be the leading international forum for presenting the latest progress, challenges and potential future directions for the EAP field. The conference this year was Chaired by Yoseph Bar-Cohen, JPL/Caltech (United States), and Co-Chaired by lain A. Anderson, The Univ. of Auckland (New Zealand) and Nancy L. Johnson, General Motors Co. (United States). This Conference has been the $21^{\text {st }}$ since its start in 1999. Presented papers reported the significant progress made in topics that included: theoretical modeling and analysis of EAP mechanisms; improved EAP materials, processes, fabrication (including additive manufacturing such as $3 D$ printing) and characterization techniques; emerging EAP actuators (including ionic, shape memory polymers, and dielectric EAP); applications of EAP materials including power generation and energy harvesting, robotics, haptic, tactile, and various sensors. The 2019 EAP-in-Action Session consisted of 12 demonstrations by teams from China, Germany, New Zealand, Switzerland, Sweden, and USA (see Appendix for the details).

On a sad note, the conference was opened with a brief acknowledgement for the late Prof. Siegfried Bauer by Martin Kaltenbrunner, Johannes Kepler Univ. Linz (Austria).

The Conference included 101 oral and poster presentations and it was well attended by internationally leading experts in the field including members of academia, industry, and government agencies from the USA and overseas. We are seeing significant improvements and breakthroughs in modelling, materials and applications for EAP. EAP with improved response were described including dielectric elastomer, hydraulically amplified self-healing electrostatic, IPMC, conducting polymers, gel EAP, carbon nanotubes, and other types. Specifically, there seems to be a continuing trend towards using dielectric elastomers as practical EAP actuators for commercial applications.

At this EAPAD Conf., there were two Keynote speakers including Ray $\mathrm{H}$. Baughman, The Univ. of Texas at Dallas (Figure 1) and Douglas A. Litteken, NASA Johnson Space Ctr. (Figure 2).

Ray's presentation, in honor of his $75^{\text {th }}$ birthday was titled: "Sixty years of fun in science and technology". In August 2001, Ray became the

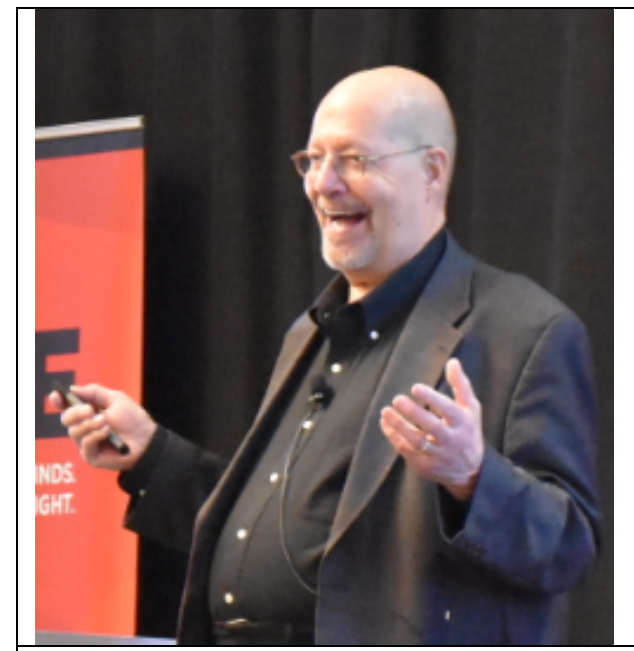

Figure 1: The Keynote Speaker Ray Baughman, NanoTech Institute, the University of Texas in Dallas

Robert A. Welch Professor of Chemistry and Director of the NanoTech Institute at the University of Texas in Dallas, after 31 years in industry. Ray is a member of the National Academy of Engineering, the Academy of Medicine, Engineering and Science of 
Texas, the Academia Europaea, and the European Academy of Sciences and Arts; a foreign member of the European Academy of Sciences; a Fellow of the Royal Society of Chemistry, the National Academy of Inventors, and the American Physical Society; an Academician of The Russian Academy of Natural Sciences; and an honorary professor of 7 universities in China.

Douglas A. Litteken was the $2^{\text {nd }}$ Keynote speaker and the title of his presentation was: "Inflatable technology: using flexible materials to make large structures". Doug is a structural engineer at NASA's Johnson Space Center (JSC) in Houston, Texas. He is the Lightweight Structures Domain Lead at JSC and a Subject Matter Expert in the agency for softgoods structures. He is also the sub-system manager for the Orion crew cabin primary structure. His interests include inflatable habitats, parachutes, composite structures, flexible electronics, and structural health monitoring. His experience includes the design, analysis and testing of softgoods structures including lunar surface habitats, airlocks, and deep space transit vehicles. He received both his

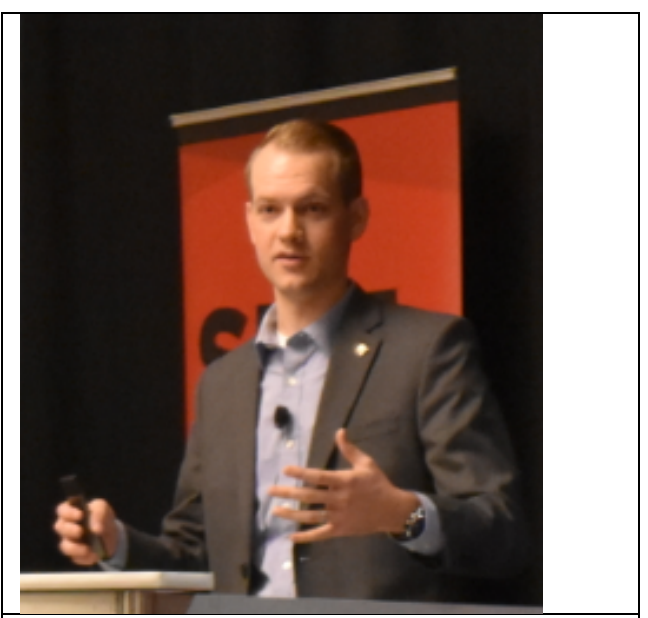

Figure 2: The Keynote Speaker Douglas Litteken, NASA's Johnson Space Center (JSC) in Houston, TX Bachelor's and Master's degrees in Mechanical Engineering from the University of Illinois at Urbana-Champaign.

The invited papers in the 2018 EAPAC Conference were:

1. Design of reliable silicone elastomers for dielectric elastomers and stretchable electronics (Paper 10966-9) - Piotr Mazurek, Liyun Yu, Anne Ladegaard Skov, Technical Univ. of Denmark (Denmark)

2. Manufacturing dielectric elastomer stack actuators: challenges and applications for industrialization (Paper 10966-29) - Helmut F. Schlaak, Technische Univ. Darmstadt (Germany)

3. From soft microrobotics to macroscopic wearables (Paper 10966-32) - Edwin W. H. Jager, Linköping Univ. (Sweden)

4. Soft electronic and robotic systems from biocompatible and degradable materials (Paper 10966-39) - Martin Kaltenbrunner, Johannes Kepler Univ. Linz (Austria)

5. Soft robotics for prosthetic devices: how dependent it is on smart materials? (Paper 10966-53)- Gursel Alici, Univ. of Wollongong (Australia)

6. Dielectric elastomer spring-roll bending actuators: applications in soft robotics and design (Paper 10966-56) - Yanju Liu, Liwu Liu, Jinsong Leng, Harbin Institute of Technology (China)

7. Soft hybrid generators for harvesting human kinetic energy (Paper 10966-72) - Claire Jean-Mistral, Institut National des Sciences Appliquées de Lyon (France); Alain Sylvestre, Lab. de Génie Électrique de Grenoble (France) 
In closing, we would like to extend a special thanks to all the conference attendees, paper presenters, session chairs, EAP-in-Action demo presenters, and the members of the EAPAD program organization committee. In addition, special thanks are extended to the SPIE staff that helped to make this conference a great success. Moreover, the Conference Chairs would like to thank Emily Power, SPIE, for providing some of the photos that were used in this Preface.

Yoseph Bar-Cohen

Iain A. Anderson Nancy L. Johnson 
Proc. of SPIE Vol. 10966 1096601-16

Downloaded From: https://www.spiedigitallibrary.org/conference-proceedings-of-spie on 26 Apr 2023 Terms of Use: https://www.spiedigitallibrary.org/terms-of-use 


\section{APPENDIX - THE 2017 EAP-IN-ACTION PROGRAM}

\section{Moderator:}

Yoseph Bar-Cohen, Jet Propulsion Laboratory

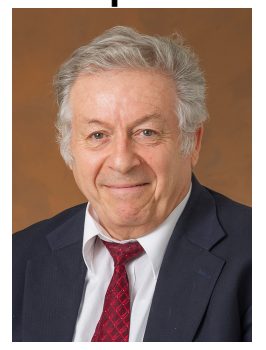

The EAP-in-Action Session of the EAPAD Conference/SPIE Smart Structures/NDE Symposia is highlighting some of the latest capabilities and applications of Electroactive Polymer (EAP) materials where the attendees are given demonstrations of these materials in action. In addition, the attendees are given opportunity to interact directly with the presenters as well as given "hands-on" experience with the presented technology. The first Human/EAP-Robot Arm wrestling Contest was held in 2005 during this session.

\section{Best EAP-in-Action Demonstration Award}

As of 2017, as part of the EAP-in-Action Session a selection is made of the "Best EAP-in-Action Demonstration". This selection is intended to encourage excellence in developing EAP materials and accelerate the transition of EAPs to practical and commercial technologies. A judging committee, consisting of leading EAP experts, selects the award winner(s) among the presenters of the demonstrations at the EAP-inAction Session. The judges assess the presenters' performance as well as the quality and content of the demos. The top ranked three are recognized and are being awarded with a certificate during the Symposium.

Evaluation criteria: The demo presenters are ranked based on the following criteria:

1. Originality/creativity

2. Use of EAP to drive the demo

3. Performance of the demo

4. Potential impact 
Scores: 4 excellent; 3 Good; 2 Fair; 1 Reasonable; 0 no show

\section{The $\mathbf{2 0 1 9}$ judges were (Figure 1):}

1. Nancy L. Johnson, General Motors Co. (United States)

2. John D Madden, The University of British Columbia (Canada)

3. Qibing Pei, University of California, Los Angeles, (UCLA), (USA)

4. Geoffrey M. Spinks, University of Wollongong (Australia)

5. Ray H. Baughman, The University of Texas at Dallas (United States)

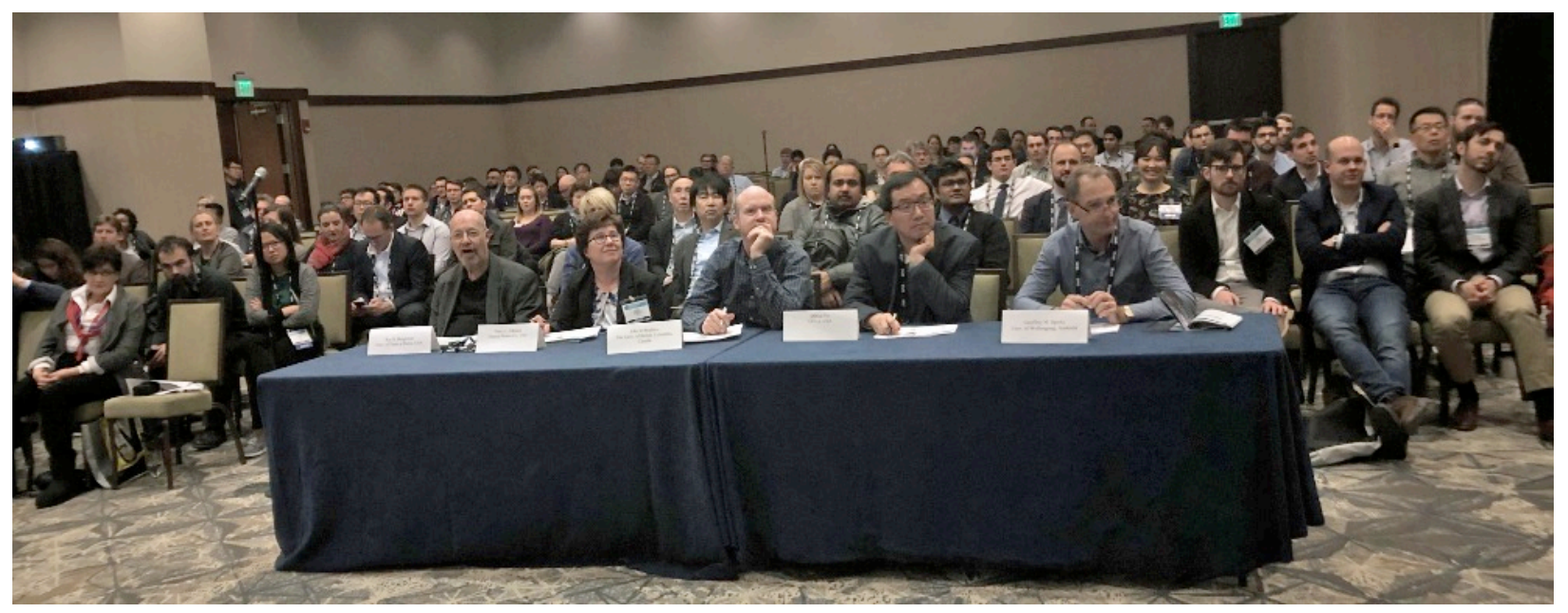

Figure 1: The judges of the EAP-in-Action best demonstrations and the audience

The 2019 EAP-in-Action Session included 11 demonstrations with presenters from China, Germany, New Zealand, Switzerland, Sweden, and USA. The presenters consisted of professors and their students as well as engineers from industry. In addition to the formal demonstration participants, presenters from the University of Colorado presented their HASEL artificial muscle actuator and a prototype that they are currently considering for commercialization (Figure 2). 


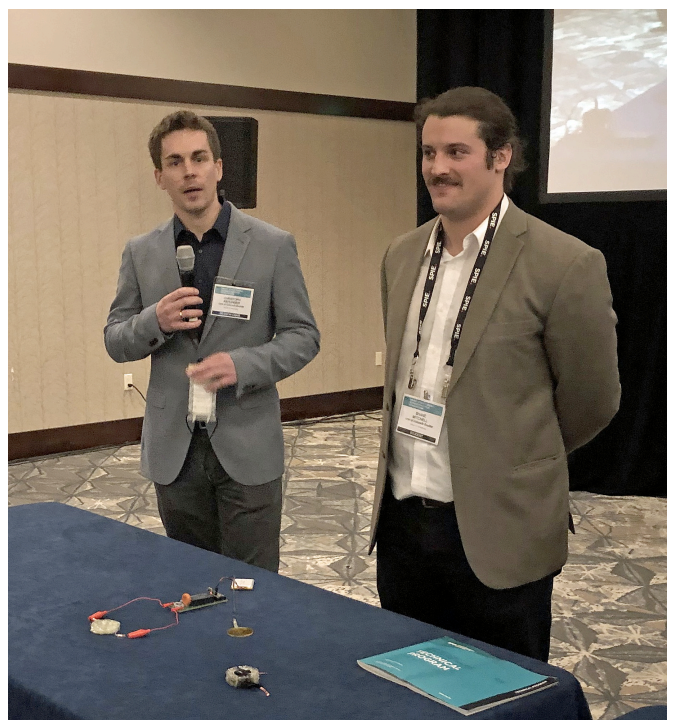

Figure 2: Members of the University of Colorado team (Christoph Keplinger and Shane Mitchell pictured) provided an impromptu demonstration of the latest developments for HASEL artificial muscles.

The top three best demonstration award recipients were:

- First Place (Figure 3): "Electro-ribbon actuators and electro-origami robots". The recipients were Tim Helps, Majid Taghavi, Richard Suphapol Diteesawat, and Jonathan M. Rossiter, Univ. of Bristol (United Kingdom) (USA).

- Second Place (Figure 4): "A fast 200 mg DEA robot". The recipient was, Herbert R. Shea, Ecole Polytechnique Fédérale de Lausanne (Switzerland)

- Third Place (Figure 5): "Synthetic muscle in prosthetics", Lenore Rasmussen, Ras Labs., Inc. (United States) 


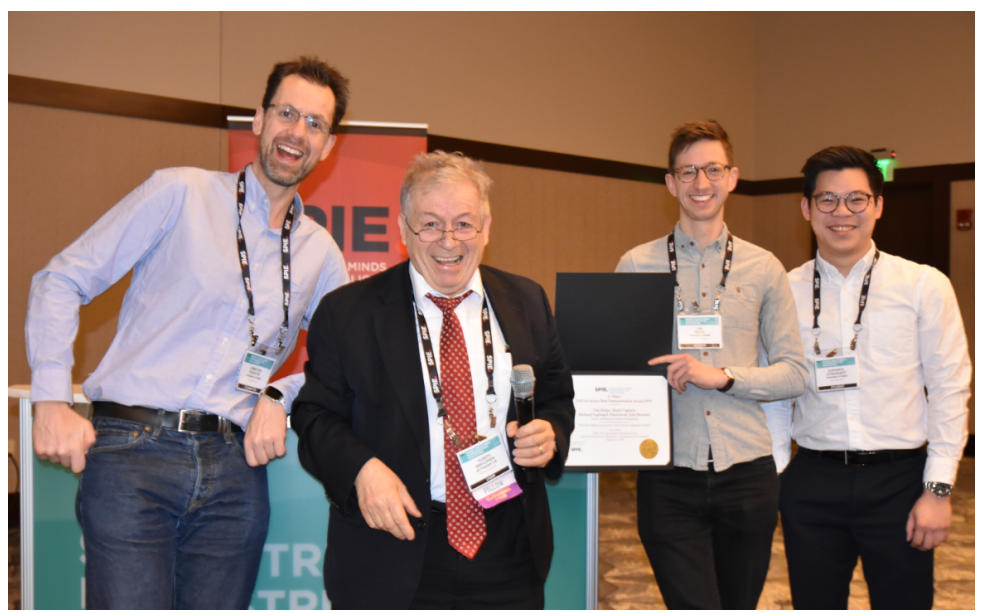

Figure 3: Recipients of the $1^{\text {st }}$ place Best EAP-in-Action Demo - The team from the University of Bristol (Jonathan Rossiter, Yosi Bar Cohen, Tim Helps and Richard Diteesawat).

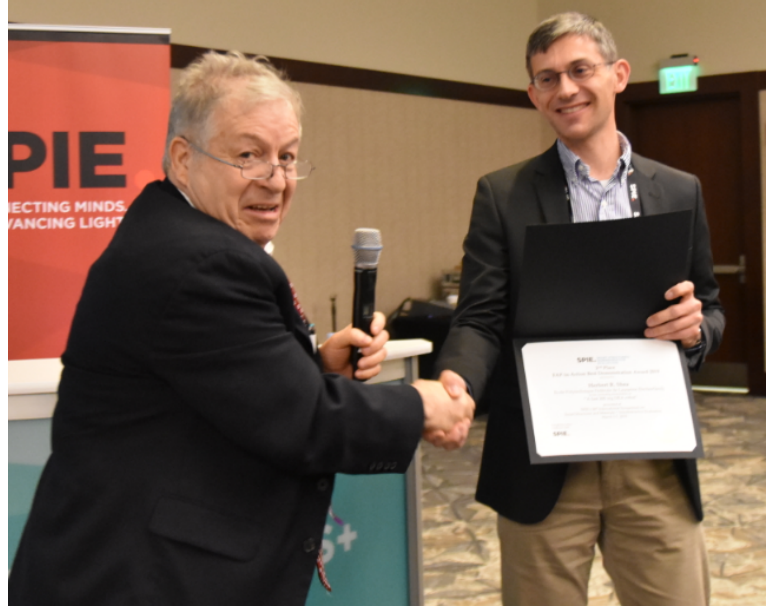

Figure 4: Yosi Bar Cohen congratulates Herb Shea, one of the recipients of the $2^{\text {nd }}$ place Best EAP-in-Action Demo. 


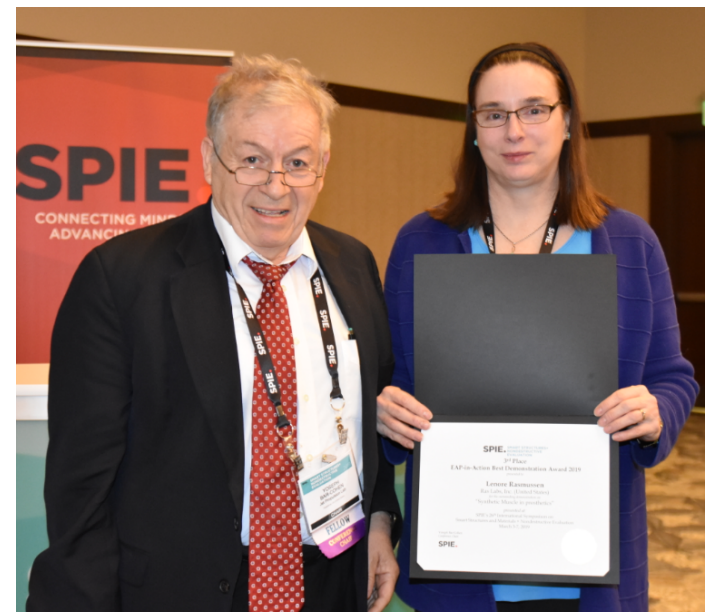

Figure 5: Yosi Bar Cohen with Lenore Rasmussen: recipient of the $3^{\text {rd }}$ place EAP-in-Action Demo.

The 2019 EAP-in-Action demonstrations included innovative devices and potential new products that are driven by EAP and they were as follows:

1. Novel dielectric elastomer membrane actuator concept for pneumatic valves - Steffen Hau, Saarland University (Germany)
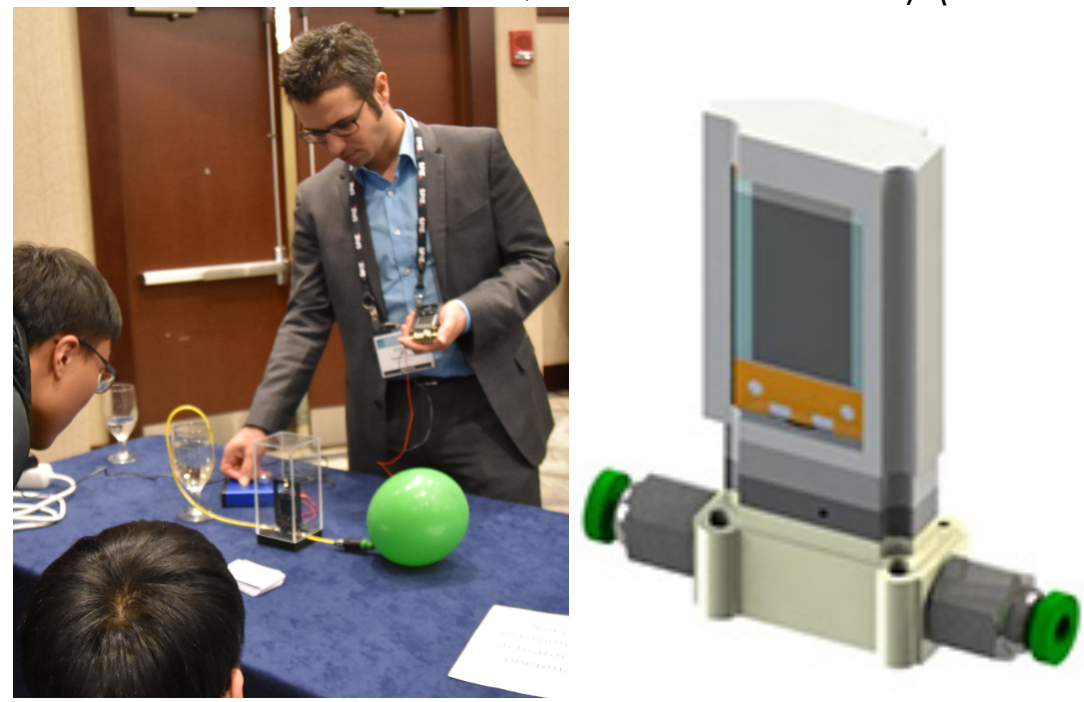

Despite being relatively easy to manufacture and providing large strokes, dielectric elastomer (DE) membrane actuators suffer from low force outputs (for single layer systems). This demo presents a novel design concept that permits to retune the stroke-force trade-off of DE actuators, by allowing increasing force output of the actuator at the expense of a reduced stroke. This is of particular interest for valve applications, which typically need high closing forces and low strokes in 
the submillimeter regime. By means of the novel design concept, the valve closing force of single DE membranes can be increased by a factor of 3 to 4 . The concepts still keeps the general advantages of DEAs, e.g., light weight, and energy efficiency. The use of strip-in-plane DE actuators additionally allows staying within the typical dimension of commercial valves.

2. DEA-based pneumatic pump - Philipp Linnebach, Saarland University (Germany)

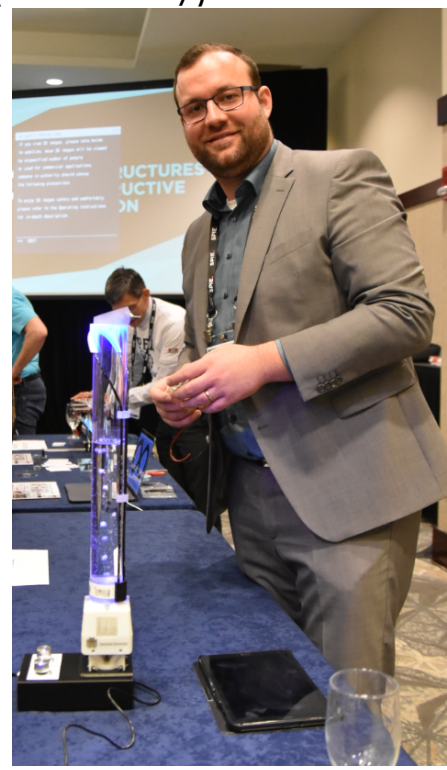

This demonstrator shows the use of circular out-of-plane dielectric elastomer actuators (COP-DEA) in a pneumatic pump application. The presented concept allows building very small and lightweight pumps. It is related to the paper with the title "Design of a dielectric elastomer actuator driven pneumatic pump". 
3. A fast $200 \mathrm{mg}$ DEA robot - X. Ji, B. Aksoy, H. Shea, EPFL (Switzerland)

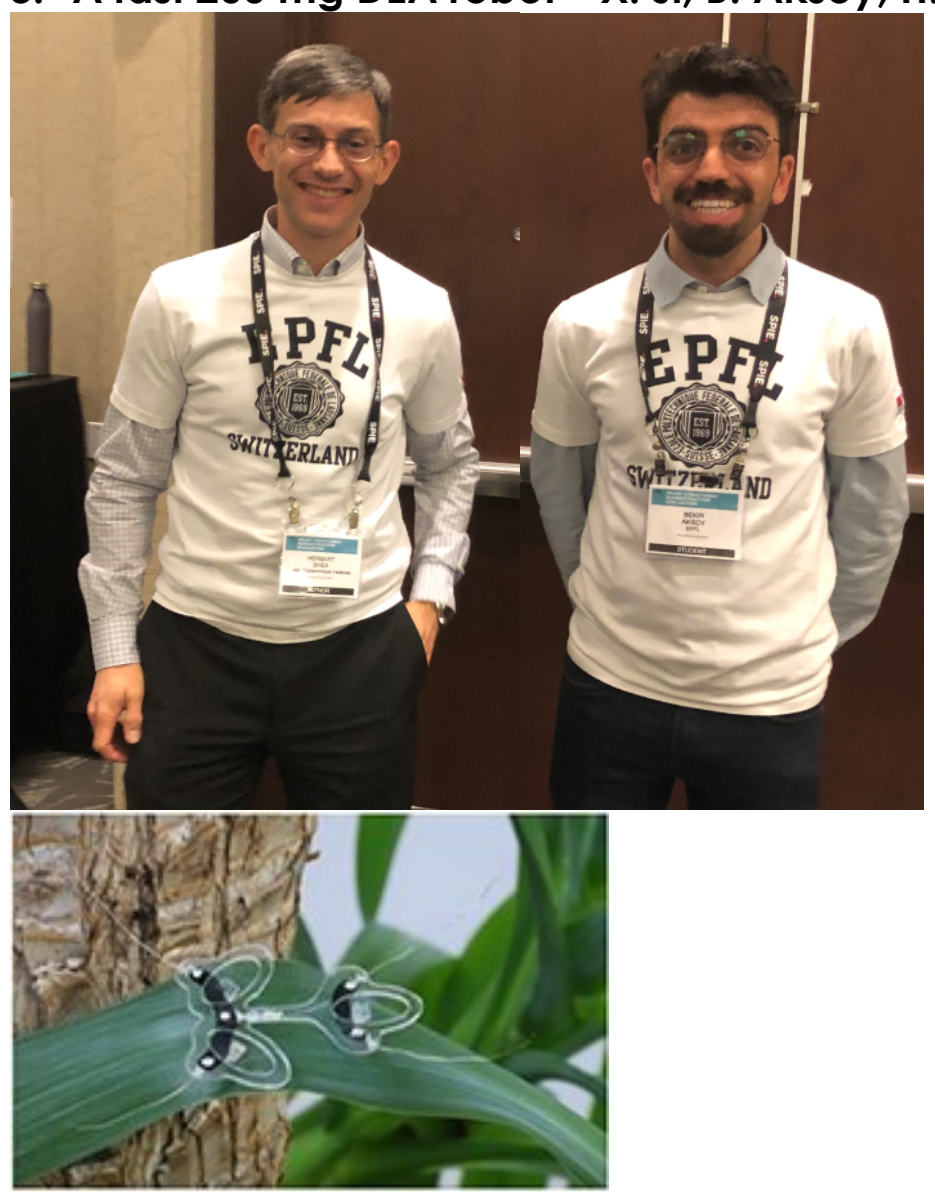

This team presented a DEAnsec, which is an ultra-light $(0.2 \mathrm{~g})$ soft robot driven by stacked dielectric elastomer actuators (DEAs) operating at 450V. The DEAnsect has a flexible silicone body and three legs, each driven independently by a DEA stack. The DEAnsect moves at four body lengths per second and can be accurately steered thanks to the independent control of each DEA. It is robust, can climb slopes of $15^{\circ}$, and survives being flattened with a fly swatter. 
4. Textile exoskeletons - Edwin W. H. Jager, Jose G. Martinez, Linkoping Univ. (Sweden), Nils-Krister Persson, Univ. of Boras (Sweden)
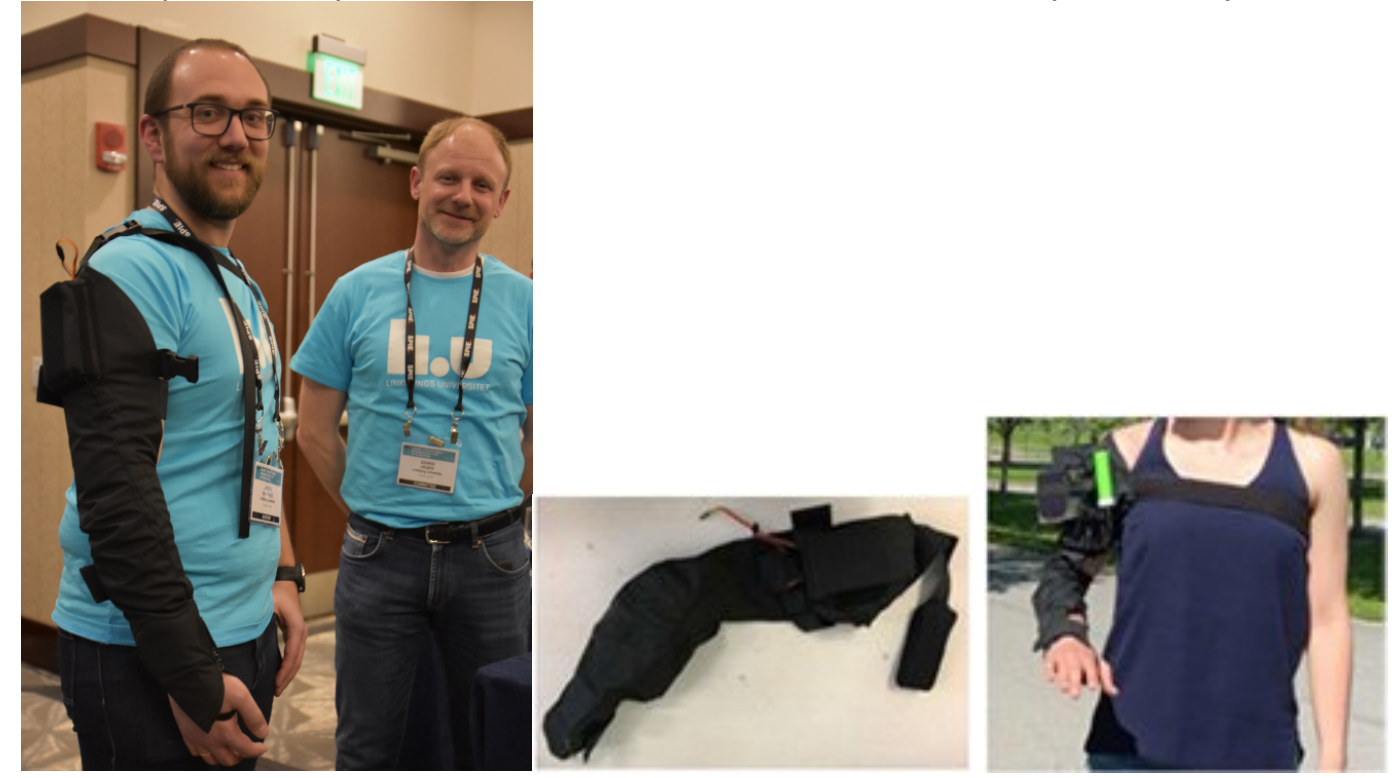

Various diseases or aging can cause a reduction in the muscle function of a person. Robotic exoskeletons have been developed to augment or replace the movement of various limbs and thus for instance assist walking or aid rehabilitation. Current exoskeletons are rigid, heavy, stiff and non-compliant. This team is developing textile-based exoskeletons that can be worn like items of clothing being light-weight, soft, compliant and comfortable. In this EAP-in-Action, demonstrators of the prototype textile exoskeleton-arm-sleeves developed by Linköping University and University of Borås was shown. The exoskeleton arm-sleeve prototypes use small electrical motors or McKibben actuators and enable lifting the arm, including a weight, of the wearer without using the user's own muscles. 
5. Smart soft polymers and structures - Liwu Liu, Qinghua Guan, Jinrong Li, Yanju Liu, Jinsong Leng, Harbin Institute of Technology (China)

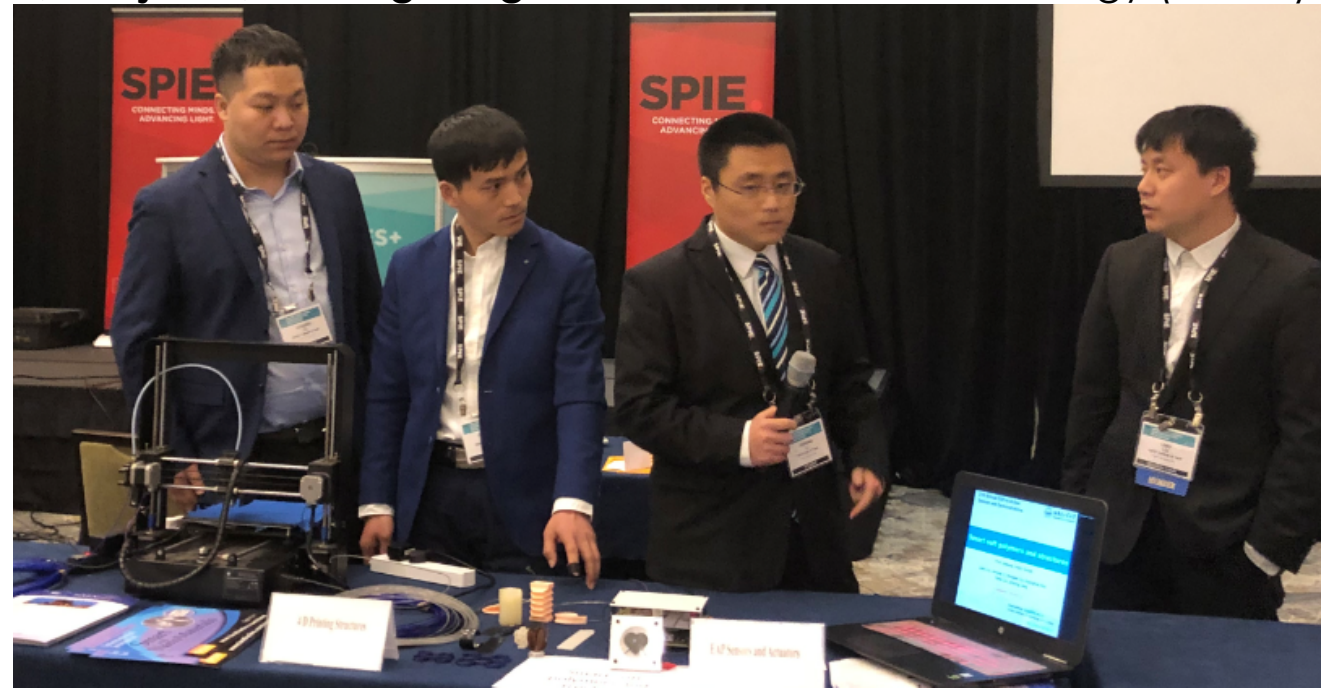

These demonstrations were focus on the applications of smart soft polymers, including dielectric elastomer (DE), shape memory polymer (SMP) and other smart soft structures. The presentations included:

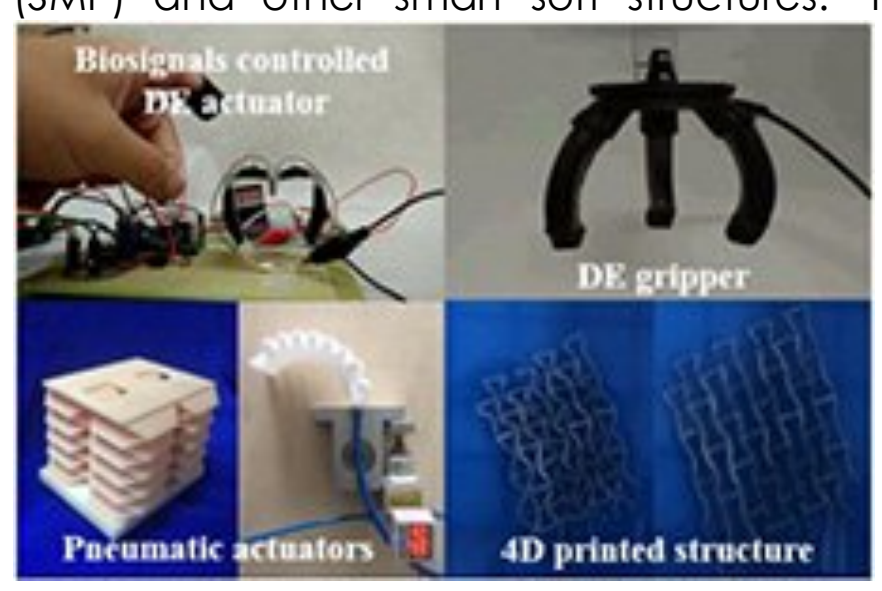

a. Biosignals controlled DE actuators - Biosignals are acquired, processed and then amplified to drive DE actuators.

b. Smart morphing structures based on DE and SMP: Structures may include deployable gripping devices or lock-release structures, etc.

c. Flexible pneumatic actuators. Multi-degree-of-freedom motions could be realized by combining multiple flexible pneumatic actuators together.

d. SMP based 4D printing technique. The 3D printable filaments with shape memory effect and some representative printed structures, which can change shape along with time, will be demonstrated. 
6. Inflatable dielectric elastomer conveyor - Joseph Ashby, E. -F. Markus Henke, Sam Rosset, Iain Anderson, Biomimetics Laboratory (New Zealand)

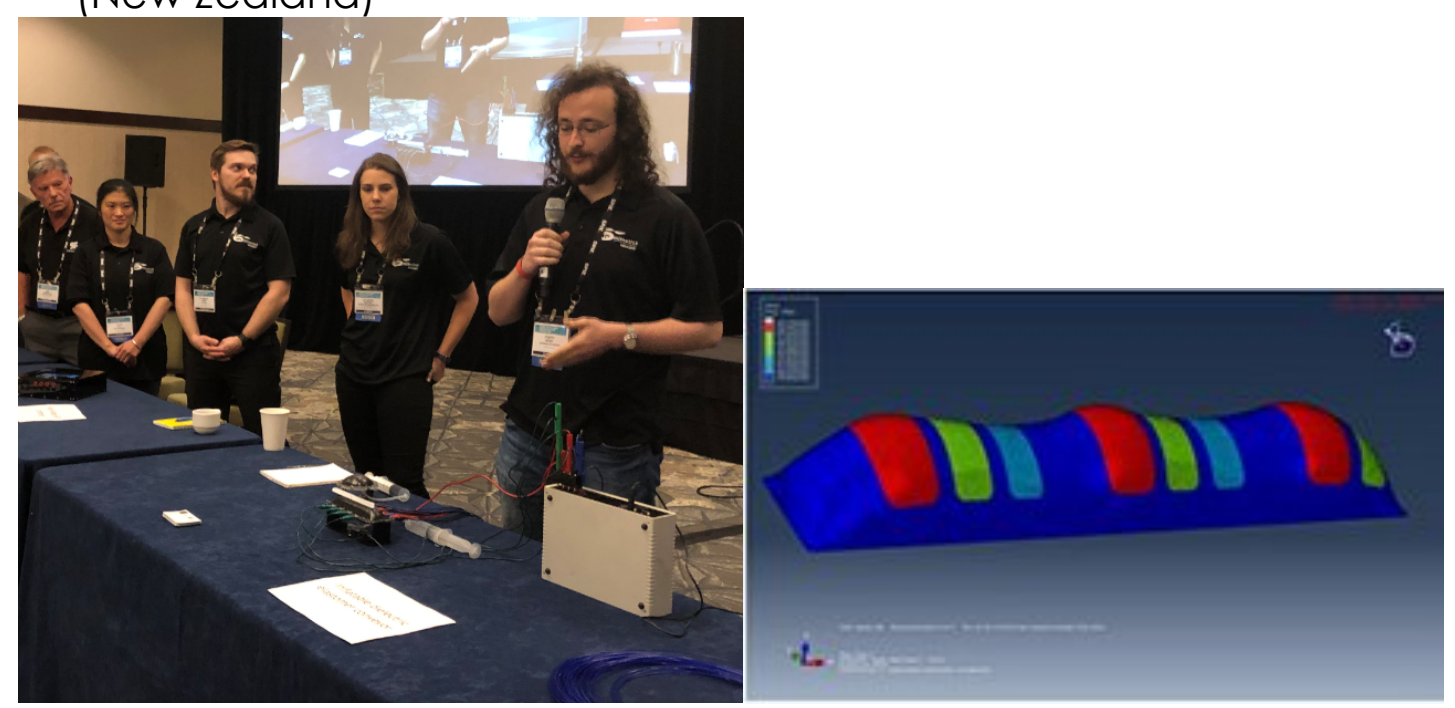

This team presented an inflatable robot, created from a sheet of silicone and airbrushed electrodes, which uses out of phase segmented actuation to produce linear conveyance of a light load along its length. In addition, they presented the results of their finite element simulation of their model. This demonstration has potential application for inflatable dielectric robotics. 
7. High voltage EAP controller - E.-F. Markus Henke,, Biomimetics Lab. (New Zealand) and TU Dresden (Germany), Patrin Illenberger, Katie Wilson, Sam Rosset, lain Anderson, Biomimetics Laboratory (New Zealand)
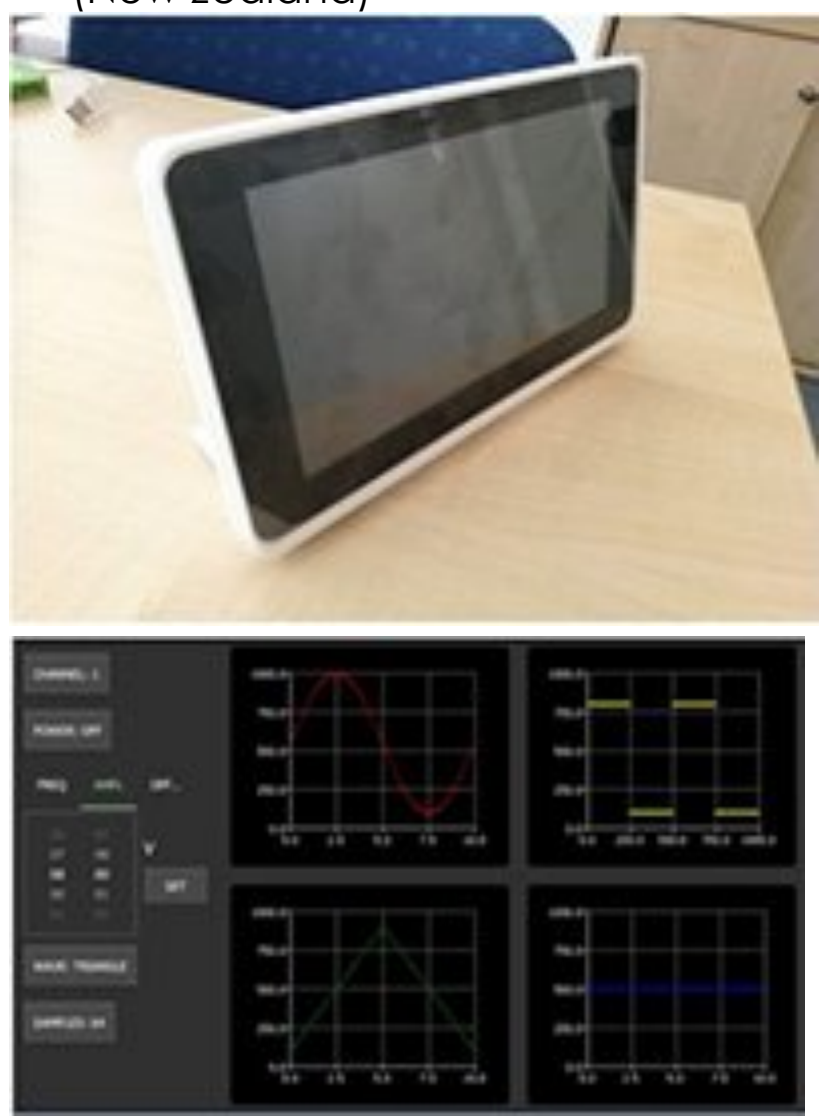

This demo is a new EAP high voltage controller that is at a stage. This new controller is intended to help university labs and other research institutions to easily power their EAP actuators without the need of developing complicated driving electronics. It comes with four channels, a touch-screen user-interface, and is battery powered. The controller provides DC, rectangle, sinusoidal and triangle signals, with an amplitude having up to $5 \mathrm{kV} @ 1 \mathrm{~mA}$ per channel. The Channels can be programmed independently. 


\section{Geometric limit switches (gDES) for robotics and automation}

industry - E.-F. Markus Henke,, Biomimetics Laboratory (New Zealand) and TU Dresden (Germany), Patrin Illenberger, Katie Wilson, Sam Rosset, lain Anderson, Biomimetics Laboratory (New Zealand)

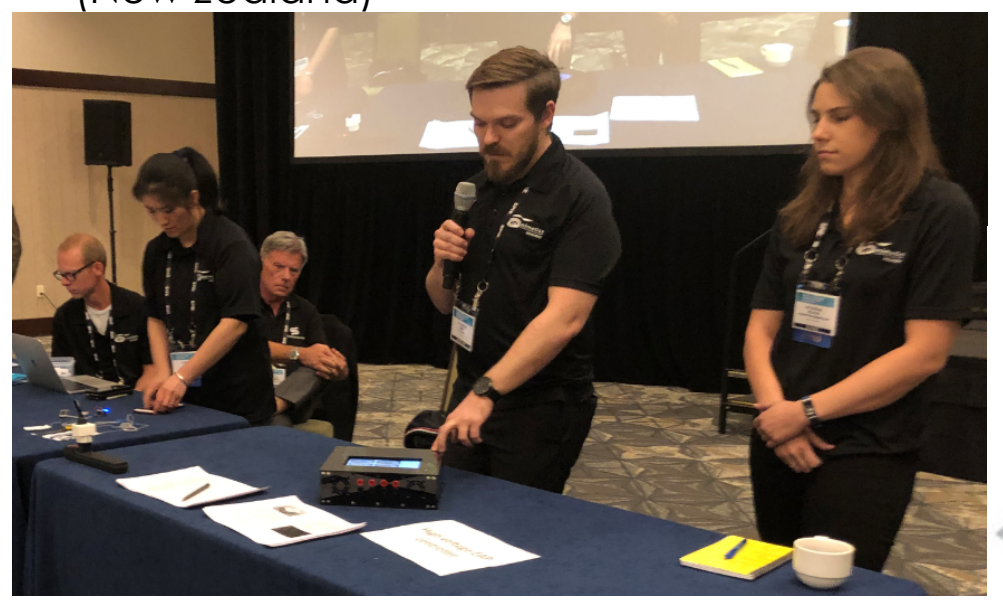

Geometric dielectric elastomer switches (gDES) have been demonstrated as a switch of both high and low voltages. They only consist of soft materials such as silicones and carbon-doped conductive silicones. Arrays of these switches can be integrated in soft robotic grippers and extend the features of those grippers by touch and shear force detection. Furthermore, gDES can act as limit switches and can be introduced in automation technology. One of the key advantages is that the switches themselves are entirely shielded and not affected by environmental influences. 
9. From StretchSense Ltd.: the latest in EAP gloves - Marco Tabor, lain Anderson, StretchSense Ltd. (New Zealand) (In the picture: Sam Rosset, lain Anderson, Yuting Zhu)
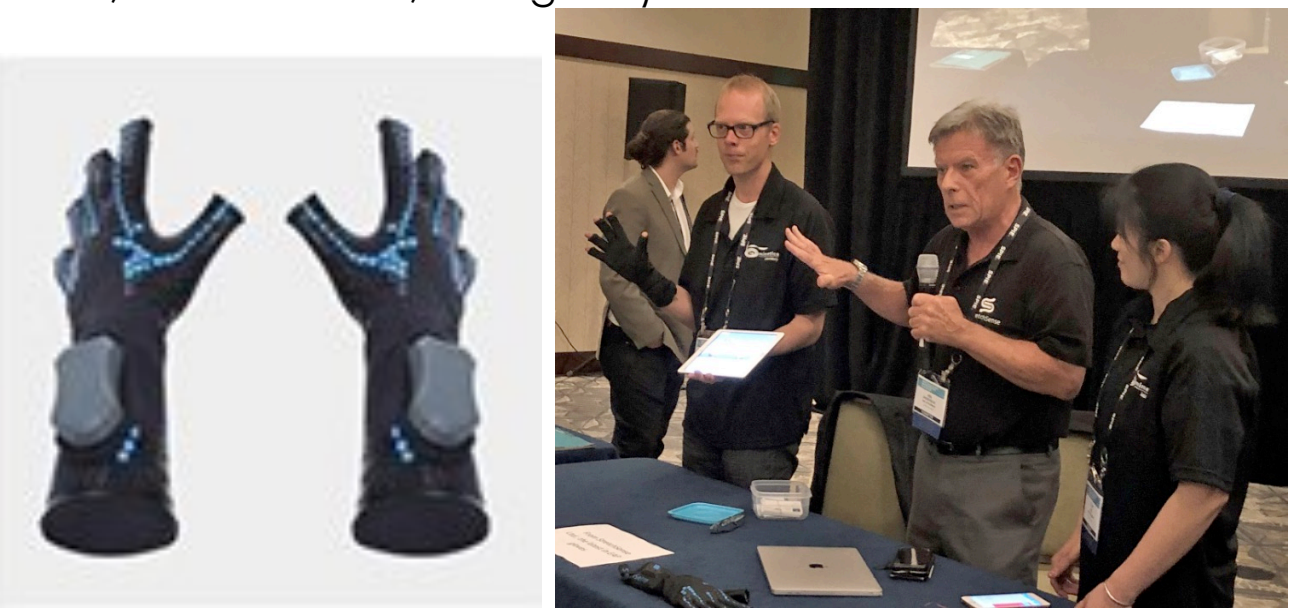

StretchSense have demonstrated their putting EAP sensors into garments using fabric-backed sensors and combining information from different sensor types. To illustrate the technology, they presented an EAP glove that can capture and send in real-time hand-posture (rotation) and finger bending to a device with an application to visualize the data e.g. game.

\section{Synthetic Muscle in prosthetics - Lenore Rasmussen, Damaris Smith,} Ras Labs, Inc. (United States)
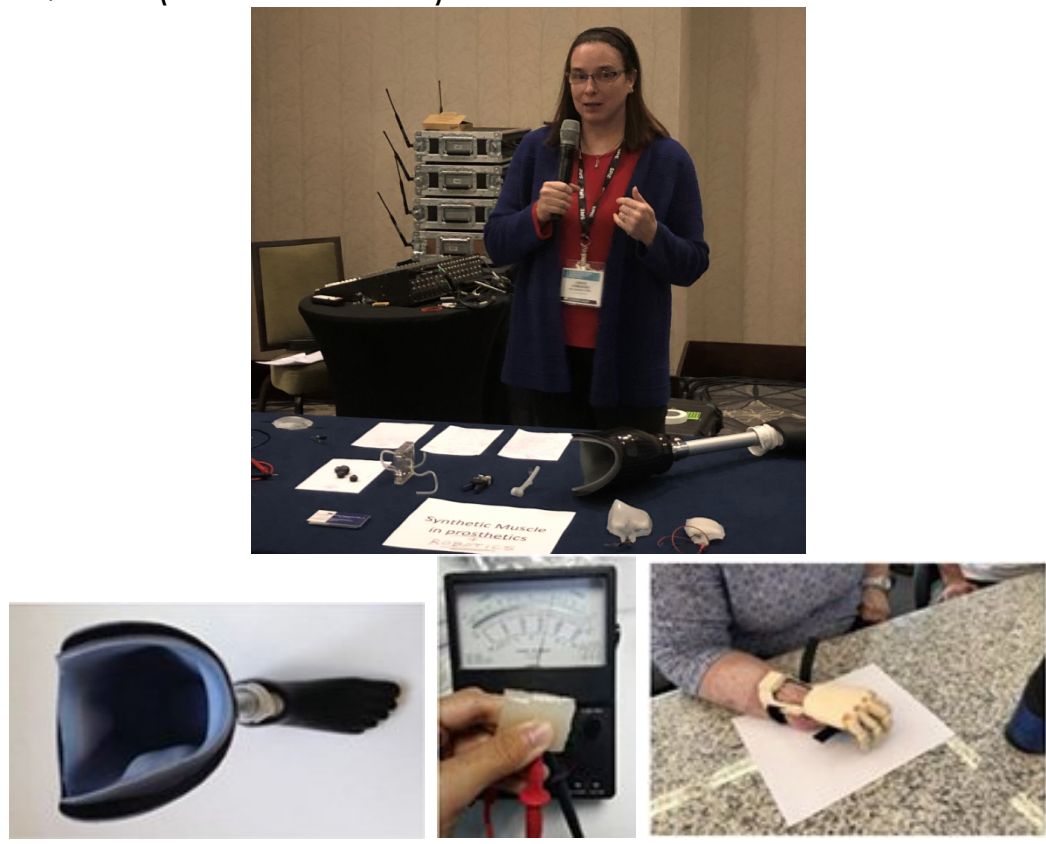


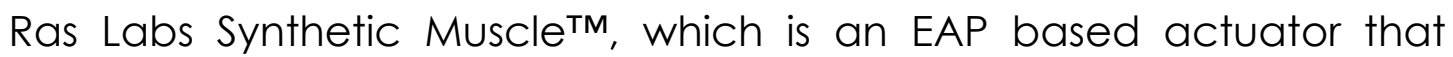
contracts, and with reversed electric input polarity, expand. Ras Labs has begun testing their EAP system on amputees to maintain continual perfect prosthetic socket fit and is going to present their prototype. These EAPs serve dual use as sensors, which can be tied in to automatic adjustment and touch biofeedback, and can determine the number of impacts (or steps) and severity of impact/pressure for protective gear and comfortable shoe wear and insoles

\section{Versatile dielectric loudspeakers - Florian Klug and Helmut F. \\ Schlaak, Technische University Darmstadt (Germany)}
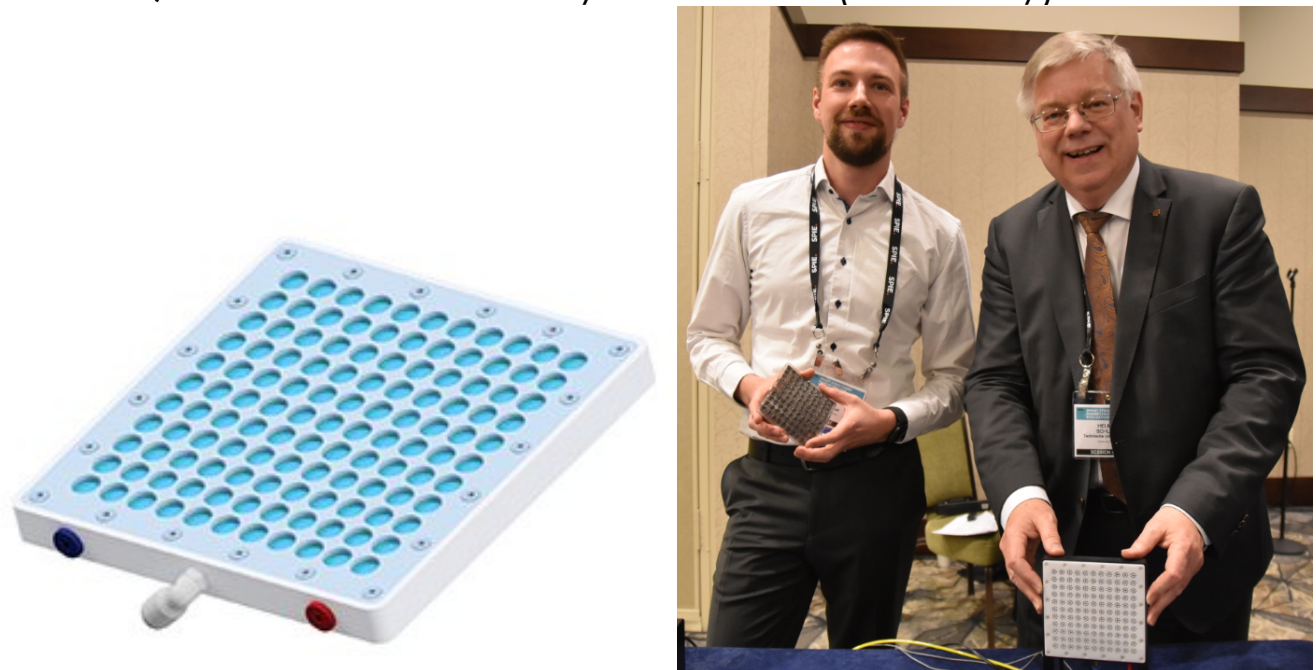

Electronic EAPs, such as the dielectric elastomer transducer, offer higher frequencies up to several kilohertz. This team presented an EAP loudspeaker. Due to their nonlinear behavior and high driving voltages, they suffer from poor audio quality and high costs. In this demonstration, the team presented a configuration for low cost, flexible or low distortion loudspeakers. Sound pressure levels higher than $100 \mathrm{~dB}$ with $<10 \mathrm{kHz}$ bandwidth and distortion $<2 \%$ depending on the configuration, they can be adaptable to various shapes and produced with large surfaces. 